\title{
THE PROTECTIVE AND THERAPY EFFECT OF APPLE PEEL ON THE EXPERIMENTAL RATS SUPPRESSED IMMUNE SYSTEM
}

\author{
By \\ EL-Sayeda Ghandour EL-Sayed EL-Sahar \\ Lecturer of Nutrition and Food Sciences, Home Economics department, Faculty of \\ Education, Ain Shams University
}

\section{Research Joupnal Specific Education \\ Faculty of Specific Education \\ Mansoura University}

ISSUE NO. 24, JAN. 2012

مجلة بحوث التربية النوعية - جامعة المنصورة 
The protective and therapy effect of apple peel on the experimental rats

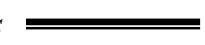

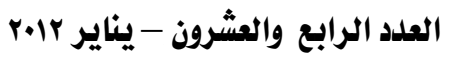




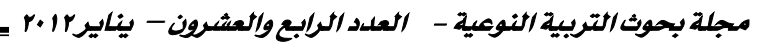

\title{
THE PROTECTIVE AND THERAPY EFFECT OF APPLE PEEL ON THE EXPERIMENTAL RATS SUPPRESSED IMMUNE SYSTEM
}

\author{
EL-Sayeda Ghandour EL-Sayed EL-Sahar \\ Lecturer of Nutrition and Food Sciences, Home Economics department, Faculty of \\ Education, Ain Shams University
}

\section{Abstract:}

This study aimed to investigate the protective and therapy effect of apple peel as food additives which may be due to increase the efficiency of the immune system or reactivity it in experimental animals. Results showed that all Gs recorded significant increases in body weight, food intake and food efficiency in the experimental period. G (1) gave significant increases in body weight, food intake and food efficiency when compared to G (2) during the first three weeks. The relative percentage of spleen weight was increased significantly in Gs (1\&2) when compared to control Gs. G (1) gave insignificant increases in percentage of spleen weight when compared to $G(2)$. RBC's count was significantly decreased in G (1) when compared to $\left(\mathrm{Co}^{+}\right)$. The same results were noticed for levels of $\mathrm{Hb}$ and Hematocrit when compared to $\left(\mathrm{Co}^{+}\right)$. The RBC's, $\mathrm{Hb}$ and hematocrit count was increased in weeks $(0,2,4$ and 6$)$, in $\mathrm{G}(2)$. G (2) gave increases in RBC,s, $\mathrm{Hb}$ and $\mathrm{HCT}$ in week 6 and $\mathrm{G}$ (1) gave decrease in MCV, MCH. The level of PLT and PCT were increased in G (1). Significant increases in Granyolocyte were detected in $\mathrm{G}$ (1) when compared to $(\mathrm{Co}+)$. The Monocyte \% and Granyolocyte were increased significantly in weeks 4 and 6 when compared to (Co-) in week 6. Urea, BUN and creatinine level were decreased in G (1), BUN/creat. Ratio gave significantly increase when compared to $\left(\mathrm{Co}^{+}\right)$. Urea level and BUN was higher in week 0 and decrease gradually in week 2, 4 and 6 in G (2). G (2) gave significant increases in urea and BUN /creat. Ratio compared to G (1). Level of AST, ALK and ALK were significantly decreased in G (1) when compared to ( $\mathrm{Co}+)$. ALT level was slight increased in serum samples of $G$ (1) when compared to $(\mathrm{Co}+)$. AST level was significantly decreased in serum samples of weeks 2,4 and 6. Similar result was found in G (2). In T.protein and T. globulin contents were increased in G (1) and the level of T. Albumin and A/G Ratio were decreased when compared to $(\mathrm{Co}+)$. T.protein was increased in week 0 and 2. The level of T. Albumin was increased in $G(2)$ in week 0 . T. Albumin was decreased after 2, 4 and 6 weeks in G (2) and slight decreases 
in the level of T. globulin in G (2) in weeks $0,2,4$ and 6 when compared to (Co-). Increases were found in T. Protein and T. Albumin in G (2) when compared to $G$ (1). IgG levels in group (1) was significantly increased. Also, slight increase in IgG ratio of T. P. was detected in group (1) when compared to $(\mathrm{Co}+)$. IgG levels and IgG Ratio of $\mathrm{T}$. Protein in group (2) were decreased when compared to (Co-) in week 0 and 2 , significant increase was detected in weeks 4 and 6. Diet reduced the MDA in Gs(1\&2) when compared to control group. When compared between two experiments group (1) gave decrease in level of MDA this indicator to the feeding before stress was the best. Results of the present study recommend that the important role to apple peel where hence they play a good role in raising the efficiency of the immune system and body protection against diseases. However, Millions of pounds of waste apple peels are generated in the production of applesauce and canned apples each year. We proposed that a valuable food ingredient could be made using the peels of these apples if they could be dried and ground to a powder without large losses of phytochemicals and use it as food additive to support and production functional food.

Key words: protective and therapy effect, Apple peel, Immune system, experimental rats suppressed, stress. 


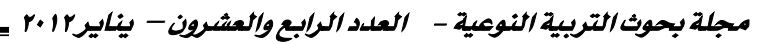

\title{
THE PROTECTIVE AND THERAPY EFFECT OF APPLE PEEL ON THE EXPERIMENTAL RATS SUPPRESSED IMMUNE SYSTEM
}

\author{
EL-Sayeda Ghandour EL-Sayed EL-Sahar \\ Lecturer of Nutrition and Food Sciences, Home Economics department, Faculty of \\ Education, Ain Shams University
}

\section{INTRODUCTION}

According to the latest research, the old saying, "An apple a day keeps the doctor away," is fact, not just folklore. The nutritional stars in apples-fiber, flavonoids, and fructose- translate into apples' able to keep us healthy (Boyer and Liu, 2004).

The apple is a member of the rose family, with a compartmentalized core which classifies it as a pome fruit or apple in Latin (Bazzano et al., 2003).

Wolfe and Liu (2003) found that there is some evidence that chronic diseases, such as cancer and cardiovascular disease, may occur as a result of oxidative stress. Apple peels have high concentrations of phenolic compounds and may assist in the prevention of chronic diseases and enhance the immune system

Liu et al., (2005) found that a major analysis of 85 studies and reported that apples were found to be most consistently associated with a reduced risk of cancer, heart disease, asthma, and type 2 diabetes when compared to other fruits and vegetables. In addition, eating apples was also associated with lung function increase and weight loss. Apples are a rich and very important source of phytochemicals, including flavonoids and phenols, when compared to other fruits, apples ranked second in total concentration of phenolic compounds, and perhaps more importantly, had the highest portion of free phenols.

Apples are also an excellent source of antioxidants, and many of the phytochemicals found in apples, including quercetin, catechin, phloridzin and chlorogenic acid, are strong antioxidants. The total antioxidant activity of 100 grams of whole apple (with the peel) was found to be equivalent to the antioxidant effect of about $1500 \mathrm{mg}$ of vitamin $\mathrm{C}$ (however, the amount of vitamin $\mathrm{C}$ in $100 \mathrm{~g}$ of apples is only about $5.7 \mathrm{mg}$. Nearly all of the antioxidant activity from apples comes from a variety of other compounds.) 
Whole apples, especially their peels, have been found to have a number of powerful antioxidant effects. Yet when quercitin, one of the most important antioxidant flavonoids in apples, was tested by itself in rats, it had no protective effect. And when apple flesh and apple juice were tested, they provided less than a tenth the benefit of whole apple (Huxley and Neil, 2003).

In several large epidemiological (population) studies conducted in the United Kingdom, Finland and the Netherlands, Van Der Sluis et al., (2002) mentioned that apple consumption (a minimum of 2 apples per week) was found to be inversely linked with asthma and type 2 diabetes, and positively associated with general lung health. Researchers attribute apples' protective effects in these conditions to apples' high concentration of antiinflammatory flavonoids, apples may also help combat cholera. Crude extracts from immature apples were found to inhibit cholera toxin in a dose dependent manner by up to $98 \%$. However, processing apples into juice greatly lowers their phytochemical content. (Heinerman, 1995).

Bazzano et al., (2003) Argued that apples contain both insoluble and soluble fiber. One medium (5 ounces) unpeeled apple provides over 3 grams of fiber, more than $10 \%$ of the daily fiber intake recommended by experts. Even without its peel, a medium apple provides 2.7 grams of fiber. Pectin grabs toxins like the heavy metals lead and mercury, and ushers them out of the body. Both the soluble and insoluble fibers in apples have cancerprotective activity since they relieve constipation and send potentially toxic substances out with the stools (thus helping to prevent diverticulosis and colon cancer). A Flavonoid Unique to Apples called phloridzin Helps Prevent Menopausal Bone Loss (Puel et al., 2005).

It's also used to treat diarrhea. One well-known over-the-counter diarrhea remedy, Kaopectate, actually contains an oxidized form of pectin (Cho et al., 2004).

Fernandez (2001) reported that a type of pigment in apples that helps provide their color which concentration in peel, flavonoids have been extensively researched and found to help prevent heart disease. Apples have long been touted as an excellent source of flavonoids that act as antioxidants, mopping up oxygen free radicals that can damage DNA. The apple flavonoids were able to protect the cells from the effects of tumor necrosis factor (TNF) by inhibiting the signals in this pathway that would otherwise damage or kill cells. Apple flavonoids protect cells from damage 
and death by interfering with communications between cells-a further mechanism than their antioxidant effects (Knekt et al., 1996).

Kern et al., (2005) studied the effect of whole apple extracts in amounts comparable to human consumption of one, three or six apples a day to prevent breast cancer in test animals. Apple peel contains high concentrations of phenols. The phenols in the skin of certain cultivars of apples may provide a hefty dose of UV-B protection (Boyer and Liu, 2004).

This study was designed to investigate the protective and therapy effect of apple peel as food additives which may be due to increase the efficiency of the immune system or reactivity it in experimental animals.

\section{MATERIALS AND METHODS}

\section{Materials:}

\section{Animals}

Thirty two male Swiss albino rats weighting from $125 \pm 2 \mathrm{~g}$. They were obtained from the National Research Center (NRC) Dokki Giza Egypt. Animals were clinically healthy and they randomized and housed in stainless steel wire bottom cages ( 3 rats / cage) and maintained in airconditioned room on a $12 \mathrm{~h} \mathrm{light/} \mathrm{dark} \mathrm{cycle} \mathrm{at} 22+2{ }^{\circ} \mathrm{C}$ and given the basal diet for one week as an adaptation period before treatments.

\section{Diet}

The composition of basal diet used in this study according to Hegsted et al., (1941) was as follows: Casein $(15 \%)$, corn oil (10\%), cellulose $(5 \%)$,Vit. Mixture (15\%), salt mixture (4\%), corn starch (65\%). The basal diet was mixed with apple peels for the experimental groups.

\section{Apple peel}

Apple was purchased from the local market, peeled then grounded before mixing with the diet and added to the basal diet in $100 \mathrm{~g} / \mathrm{kg}$ diet.

During the feeding experiments, animals were daily inspected and food intake was recorded while body weights were recorded according to (chapman et al.,1959) . The feeding experiment lasted for 6 weeks. 


\section{Experimental design}

Experimental diet and water were offered ad libitum all over the experimental period. 32 Rats were divided into four groups ( 8 rats each), the groups were used in two main experiments.

Experiment I: It included 2 groups and classified as follows: the first group was served as positive control [Co. $(+)]$ and fed on just basal diet. The second group was fed on basal diet that supplemented with apple peel. Aim of this experiment was to study the protective effect of diet supplementation on normal animals against immune suppression.

At the end of the feeding period (6 weeks), the stress was carried out (for immune suppression) then blood samples were immediately taken for analysis of hematological and immunological parameters.

Experiment $\boldsymbol{\Pi}$ : At the beginning of the experiment animals were immune suppressed by stress treatment then divided into 2 groups ( 8 rats each). The first group was served as negative control [Co. (-)] and fed on basal diet only, while the second group were fed on basal diet supplemented with apple peel.

Blood samples were taken for analysis of hematological and immunological parameters at the first day ( 0 week $)$ and then after 2 weeks, 4 weeks and at the end of the feeding period ( 6 weeks).

\section{Methods:}

\section{Stress Method (Immune suppression):-}

The rats were treated individually; each animal was put in glass tide role (tube) of the same size of the rat, to keep it without movement, the two sides of the tube closed and living some brose for respiration. Then was subjected on its back in dark refrigerator for 3-4 hours according to Riley (1981).

\section{Blood Samples:}

Blood samples were collected from orbital sinus veins by non heparinized capillary tubes $(1.5 \mathrm{ml})$. One containing EDTA (ethylenediamine tetraacetic acid) as anticoagulant $(1 \mathrm{mg} / \mathrm{ml}$ blood) and used for Haemogram parameters. The second tube (without anticoagulant), was used for the biochemical and immunological parameters. 
The coagulated blood was centrifuged at 3500 r. p. m. for 15 min., using cooling centrifuge. Serum samples prepared were divided into a liquates and kept in deep freezer at $-35^{\circ} \mathrm{C}$.

\section{Relative organ weights:}

After collection of blood samples, animals were sacrified by cervical dislocation, spleen was removed and weighted and its ratio to the total body weight was calculated, then kept in deep freezer at $-35^{\circ} \mathrm{C}$.

\section{Determination of food efficiency ratio:}

Food efficiency ratio (FER), food intake and body weight was measured according to Chapman et al., (1959).

\section{Blood analysis:}

\section{Haemogram parameters:}

Red and white blood cell counts, hemoglobin concentration, were measured according to the methods of Schalm (1986), total and differential leucocytic counts were measured according to the methods of Wintrobe (1967) and percent packed cell volume was measured according to the methods of Nemi (1986).

Mean Cell Volume (MCV), Mean Cell Hemoglobin (MCH), Mean Cell Hemoglobin Concentration (MCHC) and Red Cell Distribution Width (RDW) and addition to Platelets (PLT), Mean Platelets Volume (MPV), Platelets Distribution Width (PDW) and PCT were measured by Automated blood cell counting using an electronic blood cell analyzer, measured according to the method of Graig (1998).

\section{Biochemical analysis}

Serum urea was determined using kits of bio Merieux according to the method of Fawcett and Scott (1960), Serum creatinine and Serum transaminases, Alanine aminotransferase (ALT ) and aspartate aminotransferase (AST) were determined by using kits of Bio Merieux according to the method of Reitman and Frankel (1957), Quantitative determination of alkaline phosphatase in plasma was carried out according to Young (1975).

Plasma blood urea nitrogen was measured by quantitave enzymatic colorimetric method ( Barham and Trinder ,1972 and Fossati , 1980), Serum total protein was determined by Biuret method described by Henry 
The protective and therapy effect of apple peel on the experimental rats

(1964), Serum albumin and serum globulin was determined by bromocresol green method described by Webster (1974).

\section{Immunological parameters}

Determination of IgG concentration levels were measured with ELISA according to the method of Wiedermann et al., (1993).

The method of Begona et al., (1994) was used for the determination of lipid peroxides $\{$ Malonaldialdehyde( MDA)\}.

\section{Statistical analysis}

The significance of the main effects was determined by analysis of variance (ANOVA). The significance of various treatments was evaluated by Duncan's multiple range test $(\mathrm{P}<0.05)$. All analysis was made using a software package "Costat", a product of cohort software Berkley, California. (Duncan, 1955). 


\section{RESULTS:}

\section{Nutritional results:}

Table ( 1): Body weight, body weight gain, food intake and food efficiency of rats fed on fortificatied diet for six weeks.

\begin{tabular}{|c|c|c|c|c|c|c|c|c|c|}
\hline \multicolumn{2}{|c|}{ Treat. } & \multirow{2}{*}{$\begin{array}{c}\begin{array}{c}\text { Initial } \\
\text { Body } \\
\text { weight }\end{array} \\
126.5\end{array}$} & \multirow{2}{*}{$\begin{array}{c}\begin{array}{c}\text { Final } \\
\text { Body } \\
\text { weight }\end{array} \\
137.8\end{array}$} & \multirow{2}{*}{$\begin{array}{c}\begin{array}{c}\text { Body } \\
\text { weight } \\
\text { gain }\end{array} \\
11.3\end{array}$} & \multirow{2}{*}{$\begin{array}{c}\begin{array}{c}\text { \% Body } \\
\text { weight } \\
\text { Increase }\end{array} \\
8.9\end{array}$} & \multirow{2}{*}{\begin{tabular}{|c}
$\begin{array}{c}\text { Daily Body } \\
\text { weight } \\
\text { increase }\end{array}$ \\
1.6
\end{tabular}} & \multirow{2}{*}{$\begin{array}{c}\begin{array}{c}\text { Food } \\
\text { intake } \\
\text { g/day/ } \\
\text { group }\end{array} \\
74.8\end{array}$} & \multirow{2}{*}{$\begin{array}{c}\begin{array}{c}\text { Daily } \\
\text { Food } \\
\text { intake }\end{array} \\
10.7\end{array}$} & \multirow{2}{*}{$\begin{array}{c}\begin{array}{c}\text { Food } \\
\text { efficiency }\end{array} \\
14.3\end{array}$} \\
\hline \multirow{4}{*}{$\frac{x}{5}$} & $($ Co. +$)$ & & & & & & & & \\
\hline & G (1) & 124.5 & $146.2^{*}$ & 21.7 & 17.4 & 3.1 & $84.9 *$ & 0.0 & $25.8^{*}$ \\
\hline & (Co. -) & 123.6 & 128.6 & 5 & 4.0 & 0.7 & 57.8 & 8.3 & 8.3 \\
\hline & $G(r)$ & 126.1 & 137.1 & 11 & 8.7 & 1.6 & $77.8^{*}$ & 11.1 & $13.7^{*}$ \\
\hline \multirow{4}{*}{ 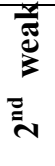 } & (Co. +$)$ & 137.8 & 149.9 & 12.1 & 8.8 & 1.7 & 84.7 & 12.1 & 14.7 \\
\hline & G (1) & 146.2 & $167.7 *$ & 21.5 & 14.7 & 3.1 & $105.2 *$ & 15.0 & $19.9^{*}$ \\
\hline & (Co. -) & 128.6 & 133.6 & 5 & 3.9 & 0.7 & 65.5 & 9.4 & 7.8 \\
\hline & G (2) & 137.1 & $151.8^{*}$ & 14.7 & 10.7 & 2.1 & $96.6^{*}$ & 13.8 & $14.6^{*}$ \\
\hline \multirow{4}{*}{ 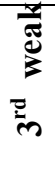 } & (Co.+) & 149.9 & 160.9 & 11 & 7.3 & 1.6 & 114.3 & 16.3 & 9.7 \\
\hline & G (1) & 167.7 & $191.3^{*}$ & 23.6 & 14.1 & 3.4 & $126.5^{*}$ & 18.1 & $19.0 *$ \\
\hline & (Co.-) & 133.6 & 140.4 & 6.8 & 5.1 & 1.0 & 77.8 & 11.1 & 8.6 \\
\hline & G (2) & 151.8 & $177.3^{*}$ & 25.5 & 16.8 & 3.6 & $118.5^{*}$ & 16.9 & $22.1^{*}$ \\
\hline \multirow{4}{*}{ 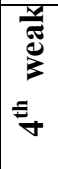 } & $($ Co. +$)$ & 160.9 & 174.9 & 14 & 8.7 & 2.0 & 124.8 & 17.8 & 11.4 \\
\hline & G (1) & 191.3 & $221.3^{*}$ & 30 & 15.7 & 4.3 & $153.2 *$ & 21.9 & $18.8^{*}$ \\
\hline & (Co.-) & 140.4 & 151.9 & 11.5 & 8.2 & 1.6 & 99.8 & 14.3 & 12.0 \\
\hline & G (2) & 177.3 & $207.6^{*}$ & 30.3 & 17.1 & 4.3 & $174.7^{*}$ & 25.0 & $17.2^{*}$ \\
\hline \multirow{4}{*}{ 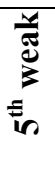 } & (Co. +$)$ & 174.9 & 191.2 & 16.3 & 9.3 & 2.3 & 173.5 & 24.8 & 8.8 \\
\hline & G (1) & 221.3 & $263.7^{*}$ & 42.4 & 19.2 & 6.1 & $207.1^{*}$ & 29.6 & $20.7^{*}$ \\
\hline & (Co. -) & 151.9 & 171.7 & 19.8 & 13.0 & 2.8 & 121.8 & 17.4 & 16.7 \\
\hline & G (2) & 207.6 & $257.3^{*}$ & 49.7 & 23.9 & 7.1 & 201.1 & 28.7 & $21.5^{*}$ \\
\hline \multirow{4}{*}{ 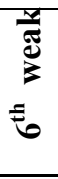 } & (Co. + ) & 191.2 & 209.3 & 18.1 & 9.5 & 2.6 & 206.1 & 29.4 & 8.6 \\
\hline & G (1) & 263.7 & $299.1^{*}$ & 35.4 & 13.4 & 5.1 & $278^{*}$ & 39.7 & $12.9^{*}$ \\
\hline & (Co. -) & 171.7 & 191.8 & 20.1 & 11.7 & 2.9 & 162.6 & 23.2 & 12.3 \\
\hline & G (2) & 257.3 & $308.2^{*}$ & 50.9 & 19.8 & 7.3 & $270.9^{*}$ & 38.7 & $18.1^{*}$ \\
\hline
\end{tabular}

*: Means on the same row differently superscripted are significantly $(\mathrm{P}<0.05)$ different.

Treat. $=$ treatment, $\mathrm{G}=$ group, $\mathrm{Co} .=\mathrm{Control}$

Data in table (1) showed that animals fed on Apple peel group (1) for 6 weeks gave significant increases in body weight, food intake and food efficiency gradually at the end of each week when compared to the negative control group. The highest increase in FER was found in the first week. 
In experiment $\Pi$, group (2) showed significant increases in body weight, food intake and food efficiency when compared to the animals under stress and fed on basal diet without supplements (negative control group). The highest increases in food efficiency was found in the $3^{\text {rd }}$ week.

Group (1) gave significant increases in body weight, food intake and food efficiency when compared to group (2) during the first three weeks. but, in the weeks (4\&5) there was no differences between groups (1) and (2) in body weight, food intake and food efficiency. After 6 weeks group (2) gave insignificant increases in body weight and food efficiency when compared to group (1).

\section{Relative spleen weight:}

Table (2): The effect of apple peel on spleen weight:

\begin{tabular}{|c|c|c|c||}
\hline Treat. & Spleen weight(mg) & Body weight (g) & \% Spleen weight \\
\hline \hline (Co. + ) & 0.4996 & 209.3 & 0.2387 \\
\hline G (1) & $0.9071^{*}$ & $299.1^{*}$ & $0.3033^{*}$ \\
\hline (Co. -$)$ & 0.3876 & 191.8 & 0.2021 \\
\hline G(2) & $0.8023^{*}$ & $308.2^{*}$ & $0.2603^{*}$ \\
\hline
\end{tabular}

*: Means on the same row differently superscripted are significantly $(\mathrm{P}<0.05)$ different.

Treat. = treatment, $\mathrm{G}=$ group, Co. $=$ Control

The effect of fortification diet on relative spleen weight of animals was illustrated in Table (2). The results showed that in animals fed supplemented diet before stress treatment (experiment I) the relative percentage of spleen weight was increased significantly (group (1)) when compared to positive control group. In immune suppressed rats (experiment $\Pi$ ) the relative percentage of spleen weight was significantly increased in group 2 when compared to negative control group.

Group (1) gave insignificant increases in percentage of spleen weight when compared to group (2). 


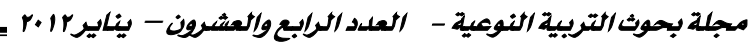

\section{Haematological results:}

The effect of apple peel on RBC's count, Hb concentration and Haematocrit:

Table (3): The effect of Appel peel on counting of erythrocytes (RBC's), hemoglobin $(\mathrm{Hb})$ and Hematocrit (HCT).

\begin{tabular}{|c|c|c|c|c|c|c|c|c|c|c|c|c|}
\hline $\begin{array}{c}\text { Treatment } \\
\text { Experiment I }\end{array}$ & \multicolumn{4}{|c|}{ RBC's } & \multicolumn{4}{|c|}{$\mathbf{H b}$} & \multicolumn{4}{|c|}{ HCT } \\
\hline Co. $(+)$ & \multicolumn{4}{|c|}{ 10.r. } & \multicolumn{4}{|c|}{21.10} & \multicolumn{4}{|c|}{$51 . \leqslant Y$} \\
\hline G (1) & \multicolumn{4}{|c|}{$7 . \vee Y *$} & \multicolumn{4}{|c|}{$10 . \leqslant 2 *$} & \multicolumn{4}{|c|}{$\varepsilon \cdot . Y^{2 *}$} \\
\hline & \multicolumn{4}{|c|}{ week } & \multicolumn{4}{|c|}{ Week } & \multicolumn{4}{|c|}{ week } \\
\hline Experiment $\Pi$ & $\mathbf{0}$ & 2 & 4 & 6 & $\mathbf{0}$ & 2 & 4 & 6 & $\mathbf{0}$ & 2 & 4 & 6 \\
\hline Co. (-) & $6 . r r$ & 7.71 & $7.0 Y$ & 1.04 & $\mid 12.8$ & $1 \Upsilon .91$ & 15.97 & 17.97 & $3^{r} . \wedge 7$ & $37.8^{\circ}$ & $r q, \wedge v$ & $40 . \wedge \wedge$ \\
\hline G(2) & $4,07 \%$ & $\left|7 . r^{\prime}\right|$ & 7.50 & ^.97* & 1 r.33 & $14 . \leqslant 8$ & 14. $\vee \wedge$ & $16.12 \%$ & $|37 . \leqslant r|$ & 37.99 & $\left|37 . r^{\circ}\right|$ & $41 . r 0 *$ \\
\hline
\end{tabular}

*: means on the same row differently superscripted are significantly $(\mathrm{P}<0.05)$ different.

Treat. $=$ treatment, $\mathrm{G}=$ group, $\mathrm{Co} .=$ Control

The results showed that, The RBC's count, $\mathrm{Hb}$ concentration and Hematocrit in Table (3). (experiment I ) RBC's count was significantly decreased in blood samples of group (1) when compared to positive control group. The same results were noticed for levels of $\mathrm{Hb}$ and Hematocrit when compared to positive control group.

In immune suppressed animals (experiment $\Pi$ ) the RBC's count was increased in blood samples of weeks (0,2, 4 and 6) ( at ascending order ), the same results were noticed for level of $\mathrm{Hb}$ and hematocrit when compared to the negative control group. The lowest decrease was found in week 0 . when compared between two experiments, group (2) gave increases in $\mathrm{RBC}, \mathrm{s}, \mathrm{Hb}$ and $\mathrm{HCT}$ at the end of the experiment. 


\section{The effect of apple peel on MCV, MCH, MCHC and RDW:}

Table (4): The effect of apple peel on (MCV), (MCH), (MCHC) and (RDW).

\begin{tabular}{|c|c|c|c|c|c|c|c|c|c|c|c|c|c|c|c|c|}
\hline $\begin{array}{c}\text { Treat. } \\
\text { Experiment I }\end{array}$ & \multicolumn{4}{|c|}{ MCV } & \multicolumn{4}{|c|}{ МСH } & \multicolumn{4}{|c|}{ МСНС } & \multicolumn{4}{|c|}{ RDW } \\
\hline Co. $(+)$ & \multicolumn{4}{|c|}{$\varepsilon 9 . \vee \wedge$} & \multicolumn{4}{|c|}{19.10} & \multicolumn{4}{|c|}{ r9.7V } & \multicolumn{4}{|c|}{$2 Y . \cdot r$} \\
\hline G (1) & \multicolumn{4}{|c|}{$5 \cdot . \wedge 4$} & \multicolumn{4}{|c|}{$19 .+1$} & \multicolumn{4}{|c|}{$3 \vee .9 \wedge *$} & \multicolumn{4}{|c|}{$2 Y . r 1$} \\
\hline & \multicolumn{4}{|c|}{ Week } & \multicolumn{4}{|c|}{ week } & \multicolumn{4}{|c|}{ week } & \multicolumn{4}{|c|}{ week } \\
\hline $\begin{array}{c}\text { Experiment } \\
\text { I }\end{array}$ & $\mathbf{0}$ & 2 & 4 & 7 & $\mathbf{0}$ & $r$ & 4 & 7 & . & $r$ & $\varepsilon$ & 1 & . & $r$ & $\varepsilon$ & 7 \\
\hline Co. (-) & $51.7 \mathrm{~V}$ & $5 r .91$ & 5 r.. 1 & 5.97 & $\begin{array}{ll}19 \\
\leq 4\end{array}$ & 19.1 & 19.4 & $21 . \leqslant \leq$ & $3 \mathbf{3}^{\mathrm{v}} 1$ & $35.4 !$ & 35.7 & $41 . \varepsilon$ & $\begin{array}{c}4 \\
1\end{array}$ & 20.6 & 20.9 & $21 . r$ \\
\hline $\mathbf{G}(2)$ & $4 \wedge . \wedge 0$ & $0 . .1 r$ & $0 . . \leqslant r$ & $51 . \leqslant 0$ & $\begin{array}{c}19.6 \\
\varepsilon\end{array}$ & $19.46 *$ & $19.72 *$ & 20.2 & $r a . \wedge q *$ & $\begin{array}{c}39.4 \% \\
*\end{array}$ & $38 . \wedge^{*}$ & 40.1 & $22 . r$ & $r r, r \mid$ & $2 r . \varepsilon$ & 21.1 \\
\hline
\end{tabular}

*: means on the same row differently superscripted are significantly $(\mathrm{P}<0.05)$ different.

Treat. $=$ treatment, $\mathrm{G}=$ group, $\mathrm{Co} .=\mathrm{Control}$

The levels of MCV, MCH, MCHC and RDW in group (1) were recorded in table (4). The results represent animals fed on supplemented diets for six weeks then put under stress (experiment I). The data showed that $\mathrm{MCH}$ and $\mathrm{MCHC}$ were decreased in blood samples. In addition, group (1) showed increasing in level of MCV and RDW of blood samples when compared to positive control group.

Animals of the second experiment showed that the level of MCV (at the beginning of the experiment and after stress treatment) was decreased in week 0,2 , and 4 when compared to negative control group. Blood samples in week 6 gave insignificant increase in MCV.

Also, the results showed that the level of $\mathrm{MCH}$ gave significant increases in week 2 and 4 in blood samples of group (2). In addition, group (2) gave significant increases in week 0,2 and 4 in MCHC when compared to negative control group. However increases were found in RDW, there was no difference found in the $6^{\text {th }}$ week when compared to negative control group.

When compared between two experiments group (1) gave decrease in $\mathrm{MCV}, \mathrm{MCH}$, and $\mathrm{MCHC}$, However gave increase in RDW at the end of the experiment. 


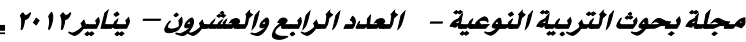

The effect of apple peel on PLT, PCT, MPV and PDW:

Table (5): The effect of apple peel on (PLT), (PCT), (MPV) and (PDW).

\begin{tabular}{|c|c|c|c|c|c|c|c|c|c|c|c|c|c|c|c|c|}
\hline $\begin{array}{c}\text { Treat. } \\
\text { Experiment }\end{array}$ & \multicolumn{4}{|c|}{ PLT } & \multicolumn{4}{|c|}{ PCT } & \multicolumn{4}{|c|}{ MPV } & \multicolumn{4}{|c|}{ PDW } \\
\hline Co. $(+)$ & \multicolumn{4}{|c|}{$\varepsilon r r$} & \multicolumn{4}{|c|}{$0.3 \vee \varepsilon$} & \multicolumn{4}{|c|}{$7 . \wedge$} & \multicolumn{4}{|c|}{$21 . \wedge$} \\
\hline G (1) & \multicolumn{4}{|c|}{$5 Y V$} & \multirow{2}{*}{\multicolumn{4}{|c|}{$\begin{array}{l}0.4 \wedge \gamma \\
\text { Week }\end{array}$}} & \multirow{2}{*}{\multicolumn{4}{|c|}{$\begin{array}{c}7 . \varepsilon \\
\text { Week }\end{array}$}} & \multirow{2}{*}{\multicolumn{4}{|c|}{$\begin{array}{l}11.7 \\
\text { week }\end{array}$}} \\
\hline & & we & eek & & & & & & & & & & & & & \\
\hline $\begin{array}{c}\text { Experiment } \\
\text { II }\end{array}$ & 0 & 2 & 4 & 1 & 0 & $r$ & 4 & 7 & . & r & $\varepsilon$ & 7 & . & $r$ & $\varepsilon$ & 7 \\
\hline \begin{tabular}{|l|} 
Co. (-) \\
\end{tabular} & TRT & $7 \cdot 3$ & 611 & 490 & $0.5 r^{q}$ & $0.7 \wedge \mathrm{V}$ & $0.5^{\circ} \leqslant$ & $0 . \leqslant 1 Y$ & 10.7 & $10 . \xi$ & 10.0 & 7.9 & $19 . \wedge$ & $21 . r$ & 23. & $12 . \mathrm{V}$ \\
\hline$G(2)$ & 790 & 794 & $6^{r} \leqslant$ & s & $0.67 \wedge$ & $0.69 \leqslant$ & $0.5 \bullet 8$ & $0.3^{\wedge \uparrow}$ & 9.9 & 9.0 & $8 . \varepsilon$ & 7.1 & $21^{\circ}$. & $18.7 *$ & $16.7 *$ & $11.0^{\circ}$ \\
\hline
\end{tabular}

*: means on the same row differently superscripted are significantly $(\mathrm{P}<0.05)$ different.

Treat. $=$ treatment, $\mathrm{G}=$ group, $\mathrm{Co} .=$ Control

The changes on PLT, PCT, MPV and PDW of animals fed on supplemented diets with apple peel were illustrated in table (5). Results showed that the level of PLT and PCT were increased in blood samples of group (1). However, MPV and PDW were decreased in blood samples when compared to positive control group.

In experiment $\Pi$, PLT of blood samples of group (2) was increased at the beginning (week 0 ) and after 2 weeks when compared to negative control group. However, after 4 and 6 weeks insignificant decreases were observed. Similar findings were noticed for blood PCT. MPV was insignificantly decreased in blood samples after weeks 0,2 and 4. At the end of the experiment MPV gave insignificant increases. PDW gave significant decreases in weeks 2 and 4 when compared to negative control group.

Blood samples showed that there was insignificant difference between groups (1) and (2) in PLT, MPV and PDW. However, group (2) gave decrease in PCT when compared between two experiments. 
The effect of apple peel on total leukocyte count (WBC's) and differential of leukocyte $(\%)$ :

Table (6): The effect of apple peel on counting of total leukocyte count (WBC's) and differential of leukocyte (\%)

\begin{tabular}{|c|c|c|c|c|c|c|c|c|c|c|c|c|c|c|c|c|}
\hline $\begin{array}{c}\text { Treat. } \\
\text { Experime } \\
\text { nt I I }\end{array}$ & \multicolumn{4}{|c|}{ WBC's } & \multicolumn{4}{|c|}{ Lym. } & \multicolumn{4}{|c|}{ Mon. } & \multicolumn{4}{|c|}{ Gra. } \\
\hline Co. $(+)$ & \multicolumn{4}{|c|}{22.5} & \multicolumn{4}{|c|}{82.2} & \multicolumn{4}{|c|}{9.1} & \multicolumn{4}{|c|}{8.7} \\
\hline G (1) & \multicolumn{4}{|c|}{$11.3^{*}$} & \multicolumn{4}{|c|}{ 71.9* } & \multicolumn{4}{|c|}{9.3} & \multicolumn{4}{|c|}{$18.8^{*}$} \\
\hline \multirow[b]{2}{*}{$\begin{array}{c}\text { Experime } \\
\text { nt II }\end{array}$} & \multicolumn{4}{|c|}{ week } & \multicolumn{4}{|c|}{ week } & \multicolumn{4}{|c|}{ week } & \multicolumn{4}{|c|}{ week } \\
\hline & 0 & 2 & 4 & 7 & $\mathbf{0}$ & $r$ & 4 & 7 & · & r & $\varepsilon$ & 7 & . & $r$ & $\varepsilon$ & 7 \\
\hline Co. (-) & 27.1 & 21 & 12.4 & \begin{tabular}{|l|}
18.2 \\
\end{tabular} & 89.5 & 89.3 & 83.6 & 79.4 & 5.8 & 5.4 & 7.9 & 8.6 & 4.7 & 5.3 & 8.5 & 12 \\
\hline G(2) & 17.4 & 15.8 & 11.2 & $11.6 *$ & $91.2 *$ & 89.3 & 70.1 & 76.3 & 5.5 & 5.2 & $8.3 *$ & 10 & 3.3 & 5.5 & $21.6^{*}$ & $13.7^{*}$ \\
\hline
\end{tabular}

*: means on the same row differently superscripted are significantly $(\mathrm{P}<0.05)$ different.

Treat. $=$ treatment, $\mathrm{G}=$ group, Co. $=$ Control

The changes on WBC's and differentiation of leukocyte of animals fed on diet supplemented with apple peel were illustrated in Table (6) Results showed that:

In experiment I (animals fed supplemented diets then put under stress) the WBC's count and lymphocyte percentage decreased significantly in blood samples when compared to positive control group. However, insignificant difference in Monocyte percentage was detected in group (1), as well as Significant increases in Granyolocyte percentage were detected in group (1) when compared to positive control group.

In experiment $\Pi$ (in immune suppressed rats) WBC's count was decreased in weeks 0 and 2 (after stress treatment and before feeding on supplemented diets) and in week 4 as well. However, At the end of the experiment WBC's count gave significant decrease. Lymphocyte percentage gave significant increase in week 0 , but didn't give difference in week 2 and 6 when compared to negative control group. 
The results in table (6) also showed that the Monocyte \% and Granyolocyte were increased significantly in blood samples of weeks 4 and 6 when compared to negative control group at the end of the experiment.

Group (2) gave increase in lymphocyte and Monocyte also gave significant decrease in Granyolocyte \%, there was no difference in WBC's when compared between two experiments.

\section{The effect of apple peel on kidney functions:}

Table (7): The effect of apple peel on Urea, Creatinine, BUN and BUN / Creatinine Ratio.

\begin{tabular}{|c|c|c|c|c|c|c|c|c|c|c|c|c|c|c|c|c|}
\hline $\begin{array}{l}\text { Treatment } \\
\text { Experime } \\
\text { nt I }\end{array}$ & \multicolumn{4}{|c|}{ Urea } & \multicolumn{4}{|c|}{ Creatinine } & \multicolumn{4}{|c|}{ BUN } & \multicolumn{4}{|c|}{ BUN/Creat. Ratio } \\
\hline Co. $(+)$ & \multicolumn{4}{|c|}{$r \cdot, \varepsilon$} & \multicolumn{4}{|c|}{0.0} & \multicolumn{4}{|c|}{10.1} & \multicolumn{4}{|c|}{31.6} \\
\hline$G(1)$ & \multicolumn{4}{|c|}{ rV.2* } & \multicolumn{4}{|c|}{$0 . \varepsilon *$} & \multicolumn{4}{|c|}{$1^{r} .7$} & \multicolumn{4}{|c|}{$34^{*}$} \\
\hline \multirow[b]{2}{*}{$\begin{array}{c}\text { Experime } \\
\text { nt } \Pi\end{array}$} & \multicolumn{4}{|c|}{ Week } & \multicolumn{4}{|c|}{ week } & \multicolumn{4}{|c|}{ Week } & \multicolumn{4}{|c|}{ week } \\
\hline & $\mathbf{0}$ & 2 & 4 & 9 & $\mathbf{0}$ & r & 4 & 7 & · & r & $\varepsilon$ & 7 & . & r & $\varepsilon$ & 7 \\
\hline Co. (-) & 34.7 & 30.1 & 32.9 & 46.3 & 0.4 & 0.5 & 0.5 & 0.5 & 16.4 & 15 & 16 & 22.9 & 41 & 30 & 32 & 45.8 \\
\hline G(2) & 45.7 & 30.3 & 30.6 & $40.2^{*}$ & 0.4 & 0.5 & 0.5 & 0.5 & 20.7 & 15.3 & 15.8 & 18.6 & 51.75 & 30.6 & 31.6 & $37.2 *$ \\
\hline
\end{tabular}

*: means on the same row differently superscripted are significantly $(\mathrm{P}<0.05)$ different.

Treat. $=$ treatment, $\mathrm{G}=$ group, Co. $=$ Control

Data in table (7) showed the changes on Urea, Creatinine, Blood Urea Nitrogen (BUN) and BUN / Creatinine ratio.

Animals fed with supplemented diet before stress treatment (experiment I) showed that, Urea and creatinine level were insignificantly decreased in serum samples of group(1). Less decreases were found in BUN. However, BUN/creat. Ratio gave significantly increase when compared to positive control group.

In experiment $\Pi$ showed that Urea level was higher in week 0 and decrease gradually in week 2 and 4 then gave significant decrease at the end of the experiment when compared to negative control group. Similar findings were noticed for BUN level.

Results also showed that the level of Creatinine had no changes in all weeks. But, BUN/Creatinine ratio was insignificantly increased in week 0 . 
However, no difference in weeks 2 and 4, at the end of the experiment found significant decrease in BUN/Creatinine ratio when compared to negative control group.

When compared between to experiments group (2) gave significant increases in urea and BUN /creat. Ratio. The results also showed that there is no difference in creatinine level. But, group (2) gave decrease in BUN level when compared to group (1).

The effect of apple peel on liver functions AST, ALT and ALK:

Table (8): The effect of apple peel on AST, ALT and ALK.

\begin{tabular}{|c|c|c|c|c|c|c|c|c|c|c|c|c|}
\hline $\begin{array}{c}\text { Treatment } \\
\text { Experiment } \\
\text { I } \\
\end{array}$ & \multicolumn{4}{|c|}{ AST } & \multicolumn{4}{|c|}{ ALT } & \multicolumn{4}{|c|}{ ALK } \\
\hline Co. $(+)$ & \multicolumn{4}{|c|}{ ris } & \multicolumn{4}{|c|}{$6^{r}$} & \multicolumn{4}{|c|}{$2 v}$. \\
\hline G (1) & \multicolumn{4}{|c|}{$16 \mathrm{~V} *$} & \multicolumn{4}{|c|}{64} & \multicolumn{4}{|c|}{$261 *$} \\
\hline \multirow{2}{*}{$\begin{array}{c}\text { Experiment } \\
\Pi\end{array}$} & \multicolumn{4}{|c|}{ Week } & \multicolumn{4}{|c|}{ Week } & \multicolumn{4}{|c|}{ week } \\
\hline & 0 & 2 & 4 & 6 & $\mathbf{0}$ & 2 & 4 & 6 & $\mathbf{0}$ & 2 & 4 & 6 \\
\hline Co. (-) & 20. & 179 & 191 & $19 \leq$ & $4^{\vee}$ & 49 & or & 57 & $35^{\circ}$ & 18. & 211 & 35. \\
\hline$G(2)$ & $2 \leqslant 1$ & $1 \leqslant \wedge *$ & $137 *$ & $17 \& *$ & $68 *$ & $3^{\mu *}$ & $30 \%$ & 47 & $5 \cdot V$ & $17 r$ & 26 . & $3 r^{9}$ \\
\hline
\end{tabular}

*: means on the same row differently superscripted are significantly $(\mathrm{P}<0.05)$ different.

Table (8): showed the changes on levels of AST, ALT and ALK.

In experiment I, level of AST and ALK were significantly decreased in serum samples of group (1) when compared to positive control group. Similar findings were noticed for ALK level. Results also showed that ALT level was slight increased in serum samples of group(1) when compared to positive control group. In experiment $\Pi$ data in table (8) also illustrated that AST level was significantly decreased in serum samples of weeks 2,4 and 6. Similar results was found in ALT. However, ALT gave increase at the beginning of the expermint when compared to positive control group.

Level of ALK was increased in weeks 0 and 4 . The highest increases were found in week 0. However, ALK level was decreased in serum samples of weeks 2 and 6 when compared to negative control group. On the other hand, ALK and AST level were increased in serum samples of group 
(2). However, decrease were found in level of ALT in group (2) when compared to group (1).

\section{The effect of apple peel on protein fractions:}

Table (9): The effect of apple peel on T. Protein, T. Albumin, T. Globulin and $\mathrm{A} / \mathrm{G}$ ratio.

\begin{tabular}{|c|c|c|c|c|c|c|c|c|c|c|c|c|c|c|c|c|}
\hline $\begin{array}{c}\text { Treatment } \\
\text { Experiment I }\end{array}$ & \multicolumn{4}{|c|}{ T. Protein } & \multicolumn{4}{|c|}{ T. Albumin } & \multicolumn{4}{|c|}{ T. globulin } & \multicolumn{4}{|c|}{ A/G ratio } \\
\hline Co. $(+)$ & \multicolumn{4}{|c|}{5.41} & \multicolumn{4}{|c|}{1.7} & \multicolumn{4}{|c|}{3.71} & \multicolumn{4}{|c|}{0.5} \\
\hline G (1) & \multicolumn{4}{|c|}{5.71} & \multicolumn{4}{|c|}{1.5} & \multicolumn{4}{|c|}{4.21} & \multicolumn{4}{|c|}{0.4} \\
\hline \multirow[b]{2}{*}{ Experiment II } & \multicolumn{4}{|c|}{ Week } & \multicolumn{4}{|c|}{ Week } & \multicolumn{4}{|c|}{ week } & \multicolumn{4}{|c|}{ Week } \\
\hline & $\mathbf{0}$ & 2 & 4 & 9 & $\mathbf{0}$ & $r$ & 4 & 9 & . & $r$ & $\varepsilon$ & 7 & . & r & $\varepsilon$ & 7 \\
\hline Co. (-) & 5.4 & 5.6 & 6.3 & 7.5 & 1.8 & 1.8 & 1.8 & 1.7 & 3.6 & 5.6 & 4.5 & 5.7 & 0.5 & 0.3 & 0.4 & 0.3 \\
\hline$G(2)$ & 5.7 & 5.8 & 6.3 & 6.7 & 2.2 & 1.7 & 1.7 & 1.6 & 3.5 & 4 & 4 & 4 & 0.6 & 0.4 & 0.4 & 0.4 \\
\hline
\end{tabular}

*: means on the same row differently superscripted are significantly $(\mathrm{P}<0.05)$ different.

Treat. $=$ treatment, $\mathrm{G}=$ group, Co. $=$ Control

The effect of apple peel on serum total protein, Albumin and globulin of treated animals were studied and the obtained results are given in Table (9).

In experiment I, total serum protein and total globulin contents were increased in blood samples of group (1) when compared to positive control group. The level of total Albumin and A/G Ratio were decreased in serum samples of group (1) when compared to positive control group.

In experiment $\Pi$ the contents of total serum protein were increased in serum samples in week 0 and 2 . However, slight decrease in total serum protein was detected in week 6 .

The level of total Albumin was increased in serum samples of group (2) in week 0. However, total serum Albumin was insignificantly decreased after 2, 4 and 6 weeks in group (2) when compared to negative control group.

Slight decreases in the level of total globulin in group (2) in weeks 0 , 2, 4 and 6 when compared to negative control group. 
The level of $\mathrm{A} / \mathrm{G}$ ratio was increased in serum samples of group (2) in weeks 0,2 and 6 . However, there were no differences between groups in week 4 when compared to negative control group.

On the other hand, increases were found in T. Protein and T. Albumin in group (2) when compared to group (1), less decrease was noticed in total globulin in group (2). However, no difference between groups in $\mathrm{A} / \mathrm{G}$ ratio.

\section{Immunological results:}

\section{Effect of apple peel on Immunoglobulin:}

Table (10): The effect of apple peel on Immunoglobulin $\mathrm{G}$ (IgG), IgG Ratio of globulin and IgG Ratio of T. Protein

\begin{tabular}{|c|c|c|c|c|c|c|c|c|c|c|c|c|}
\hline \multirow{2}{*}{ Treat. } & \multirow{2}{*}{\multicolumn{4}{|c|}{ IgG }} & \multicolumn{8}{|c|}{ IgG Ratio } \\
\hline & & & & & \multicolumn{4}{|c|}{ of.globulin } & \multicolumn{4}{|c|}{ of T.P. } \\
\hline Co. $(+)$ & \multicolumn{4}{|c|}{232} & \multicolumn{4}{|c|}{70.54} & \multicolumn{4}{|c|}{47.79} \\
\hline G (1) & \multicolumn{4}{|c|}{$258 *$} & \multicolumn{4}{|c|}{67.76} & \multicolumn{4}{|c|}{49.7} \\
\hline \multirow[b]{2}{*}{$\begin{array}{c}\text { Experiment } \\
\Pi\end{array}$} & \multicolumn{4}{|c|}{ Week } & \multicolumn{4}{|c|}{ Week } & \multicolumn{4}{|c|}{ week } \\
\hline & $\mathbf{0}$ & 2 & 4 & 6 & 0 & 2 & 4 & 6 & 0 & 2 & 4 & 6 \\
\hline Co. (-) & 340 & 322 & 276 & 253 & 94.4 & 57.5 & 61.3 & 44.4 & 62.96 & 57.50 & 43.81 & 33.73 \\
\hline G(2) & 337 & 318 & $320 *$ & $285 *$ & 96.3 & 79.5 & 80.0 & 71.3* & 59.12 & 54.83 & 50.79 & 42.54 \\
\hline
\end{tabular}

*: means on the same row differently superscripted are significantly $(\mathrm{P}<0.05)$ different.

Treat. $=$ treatment, $\mathrm{G}=$ group, $\mathrm{Co} .=\mathrm{Control}$

Table (10) showed that animals in experiment I represent that serum IgG levels in group (1) was significantly increased. Less decrease in IgG ratio of globulin was detected in group (1). Also, slight increase in IgG ratio of T. P. were detected in group (1) when compared to positive control group.

In experiment $\Pi$, data in table (10) showed that serum IgG levels in group (2) were decreased when compared to negative control in week 0 and 2. Significant increase was detected in weeks 4 and 6 , similar results were finding in IgG Ratio of T. Protein. Increases in IgG ratio of total globulin were detected in all of the weeks when compared to negative control group. 
At was noticed that the significantly improvement in immune response were detected in animals of experiment I better than groups of experiment $\Pi$. This may be due to the feeding of supplements for a period after stress treatment.

\section{The effect of apple peel on lipid peroxidation (MDA):}

Table (11): The effect of apple peel on MDA (nmoles/100 mg spleen).

\begin{tabular}{|c|c||}
\hline Treatment & MDA \\
\hline Co. (+) & 0.5 \% * \\
\hline G (1) & $0.3 \vee \vee$ \\
\hline Co. (-) & $1.1 \wedge \vee *$ \\
\hline G(2) & $0 . £ \vee 々$ \\
\hline
\end{tabular}

The effect of apple peel was evaluated for it's effect on lipid peroxidation of spleen tissue. The determination of malondialdehyde (MDA) content in the extract of spleen cells was proceeded as an indicator for that effect (lipid peroxidation). The values of MDA obtained for the different groups of animals are given in table (11).

In experiment I, diet reduced the MDA when compared to positive control group. In experiment $\Pi$, diet reduced the MDA when compared to negative control group. When compared between two experiments group (1) gave decrease in level of MDA this indicator to the feeding before stress was the best.

\section{Discussion:}

The diet supplement with (apple peel $75 \mathrm{~g} / \mathrm{Kg}$ diet + Honey $100 \mathrm{~g} / \mathrm{Kg}$ diet + Yogurt $150 \mathrm{~g} / \mathrm{Kg}$ diet) were evaluated for their effects on body weight, body weight gain and food efficiency ratio. Gave significant increases in body weight, body weight gain and food efficiency ratio for the group of animals are given in tested supplemented diet (after suppressed their immune system) when compared to positive control group. In the other experiment (before suppressed their immune system) the tested diet also increasing the body weight, body weight gain and food efficiency ratio when compared to negative control group (EL-Sayed, 2007).

Significant increases detected in the relative percentage of spleen weight in immune suppressed rats animals before and after feeding on diets 
containing (apple peel $75 \mathrm{~g} / \mathrm{Kg}$ diet + Honey100g $/ \mathrm{Kg}$ diet + Yogurt $150 \mathrm{~g}$ /Kg diet) when compared to control groups (EL-Sayed, 2007).

In immune suppressed rats animals before and after feeding on diets containing (apple peel $75 \mathrm{~g} / \mathrm{Kg}$ diet + Honey $100 \mathrm{~g} / \mathrm{Kg}$ diet + Yogurt $150 \mathrm{~g}$ /Kg diet) RBC's count was significantly decreased in blood samples when compared to control groups, The same results were noticed for levels of $\mathrm{Hb}$ and Hematocrit for the group of animals are given in tested supplemented diet (after suppressed their immune system) when compared to positive control group. However, the level of $\mathrm{Hb}$ gave increases but Hematocrit was decreased in blood samples in immune suppressed animals when compared to negative control group (EL-Sayed, 2007).

The results represent by EL-Sayed (2007) demonstrated that animals fed on supplemented diets with apple peel for six weeks then put under stress. The data showed that $\mathrm{MCV}, \mathrm{MCH}, \mathrm{MCHC}$ and $\mathrm{RDW}$ were decreased in blood samples when compared to positive control group.

Blood samples in animals after suppressed their immune system in week 6 gave increase in MCV. Also, the results showed that the level of $\mathrm{MCH}$ gave increases in week 2 and 4 in blood samples of animals fed on diet supplemented with (apple peel $75 \mathrm{~g} / \mathrm{Kg}$ diet + Honey $100 \mathrm{~g} / \mathrm{Kg}$ diet + Yogurt $150 \mathrm{~g} / \mathrm{Kg}$ diet). In addition, blood samples gave increases in week 0 , 2 and 4 in MCHC and RDW. There was no difference found in the 6th week when compared to negative control group.

The level of PLT and MPV was increased in blood sample. PCT have differences in blood sample. But, PDW was decreased in blood sample of animals fed on supplemented diets with apple peel for six weeks then put under stress.

Similar findings were noticed for blood PCT. MPV was insignificantly decreased in blood sample in immune suppressed animals, PDW was high in week 0 . While at week 2 and 4 gave significant decreases. After six week PDW was decreased in blood sample when compared to negative control group (EL-Sayed, 2007).

Daughenbaugh et al., (2011) investigated the effects of apple peel and purified procyanidins on T-cell gene expression. A microarray analysis was performed on bovine $\mathrm{T}$ cells treated with apple peel; increases in transcripts encoding granulocyte-monocyte colony stimulating factor, IL-8 and IL-17. 
The results represent by EL-Sayed (2007) demonstrated that the animals fed supplemented diets with apple peel then put under stress) the WBC's count and lymphocyte percentage decreased significantly in blood sample when compared to positive control group. However, insignificant decreases in Monocyte percentage were detected. Significant increases in Granyolocyte percentage were obtained when compared to positive control group.

In immune suppressed rats the fed on apple peel WBC's count was decreased in blood samples in week 0 (after stress treatment and before feeding on supplemented diets) and in week 2 as well. However, in week 4, WBC's count gave insignificant decreases after six week when compared to negative control group. Monocyte \% was increased significantly in blood sample after 2 weeks. However, decreases were found in week 6 . Monocyte $\%$ was increased in blood sample after 4 weeks. However, increases in Monocyte $\%$ and granyolocyte were obtained when compared to negative control group at the end of the experiment.

The animals fed with supplemented diets before stress treatment showed that, Urea and BUN levels was decreased in serum samples when compared to positive control group. Similar findings were noticed for level of Creatinine and BUN/Creatinine ratio. The immune suppressed animals then fed on diets containing the apple peel for six weeks showed that Urea level was higher in week 0 when compared to negative control group. Similar findings were noticed for BUN level while after 2 weeks Urea and BUN gave slight decreases. Level of Urea and BUN was decreased at the end of the experiment.

Results also showed that the level of Creatinine and BUN/Creatinine ratio have no changes in week 0 and 2. However the level of Creatinine was increased after 4 weeks. At the end of the experiment different diets have no influence on the level of Creatinine when compared to negative control group. BUN/Creatinine ratio was significantly increased after 4 weeks, at the end of the experiment, BUN/Creatinine ratio was significantly decreased when compared to negative control group (EL-Sayed, 2007).

In vivo, this flavonoid mixture (obtained from apple peel) significantly lowered plasma creatinine and urea concentration, both indicating a better postoperative kidney functions Norren et al., (2003). 
The effect of apple peel on AST level was significantly decreased in serum sample when compared to positive control group. Similar findings were noticed for ALK level and ALT level was significantly increased in serum sample.

The immune suppressed animals then fed on diets containing the apple peel for six weeks showed that AST level was decreases in serum sample when compared to positive control group (week 0 and 2). But in week 4 and 6 level of AST was significantly deceased in serum sample when compared to negative control group. However, the level of ALT was significantly increased in serum sample when compared to negative control group (week $0)$.

Decreases in level of ALT were detected in weeks 2 and 4. Similar findings were noticed for ALT in week 6, the level of ALK was increased in week 0 and 4 . However, ALK level was decreased in serum sample at the end of the experiment when compared to negative control group (ELSayed, 2007).

To evaluate the effect of apple components on cecal fermentations and lipid metabolism, rats were fed diets containing $5 \mathrm{~g} / 100 \mathrm{~g}$ apple pectin (PEC), $10 \mathrm{~g} / 100 \mathrm{~g}$ high polyphenol freeze-dried apple (PL) or both (PEC + $\mathrm{PL})$. The cecal $\mathrm{pH}$ was slightly acidic only in rats fed the PEC + PL diet as control. The cecal short-chain fatty acid pool was enlarged by all the apple fractions, with a peak of $560 \mu \mathrm{mol}$ in rats fed the PEC + PL diet compared with $189 \mu \mathrm{mol}$ in controls. Liver cholesterol and triglyceride concentrations were lower in rats fed the PEC and PEC + PL diets. Fecal bile acid excretion was markedly reduced, whereas sterol excretion was significantly increased by dietary PEC. Rats fed the PEC and PEC + PL diets also had lower apparent cholesterol absorption than controls. In, apple pectin and the polyphenol-rich fraction were more effective when fed combined together than when fed separately on large intestine fermentations and lipid metabolism, suggesting interactions between fibers and polyphenols of apple (Aprikian et al., 2003).

Also Wolfe and Liu (2003) recorded that The apple peel powder had a total antioxidant activity of $1251 \pm 56 \mu \mathrm{mol}$ vitamin $\mathrm{C}$ equivalents $/ \mathrm{g}$, similar to fresh Rome Beauty peels on a fresh weight basis $(p>0.05)$. One gram of powder had an antioxidant activity equivalent to $220 \mathrm{mg}$ of vitamin C. The freeze-dried apple peels also had a strong antiproliferative effect on 
HepG2 liver cancer cells with a median effective dose (EC50) of $1.88 \pm$ $0.01 \mathrm{mg} / \mathrm{mL}$.

Wolfe et al., (2003) demonstrated that the apple peels were also shown to more effectively inhibit the growth of HepG2 human liver cancer cells than the other apple components. This effect resulting from the peels all had significantly higher total antioxidant activities than the flesh + peel and flesh of the apple varieties examined. Idared peels had the greatest antioxidant activity (312.2 $\pm 9.8 \mu \mathrm{mol}$ of vitamin $\mathrm{C}$ equivalents/g of peels).

Apple juice intake had a pro-oxidant effect on plasma proteins in both humans and rats (Breinholt et al., 2003 and Young et al., 1999).

Total serum protein and total globulin contents were increased in blood sample of animals fed supplemented diets with apple peel then put under stress, slight decrease in level of total Albumin was noticed in rats, the level of $\mathrm{A} / \mathrm{G}$ ratio was decreased in serum sample when compared to positive control group. The immune suppressed animals then fed on diets containing the apple peel for six weeks showed that the contents of total serum protein were increased in serum sample in week 0 and 2 . On the other hand, less decreases in these fraction were detected at the end of the experiment.

The level of total Albumin was significantly increased in serum sample. However, total serum Albumin was insignificantly decreased after 2, 4 and 6 weeks. Slight decreases detected in the level of total globulin in weeks $0,2,4$ and 6 . The level of $\mathrm{A} / \mathrm{G}$ ratio was increased in serum sample in week 0 . However, there were no differences in rats in week 2, 4 and 6 when compared to negative control group (EL-Sayed, 2007).

Holderness et al., (2011) demonstrated that the tetrameric and pentameric procyanidins from apple peel have greater specificity for $\mathrm{T}$ cells, whereas larger oligomers demonstrate less specificity.

Hedges et al., (2011) reported that Oligomeric procyanidins (OPCs) have been shown to have antiviral and immunostimulatory effects. OPCs isolated from non-ripe apple peel, OPCs exhibited direct antiviral activity. OPCs also enhanced expression of critical innate antiviral products during DENV infection of human. To test the effects of OPC ingestion in vivo, mice were fed a rich source of OPCs and injected with polyIC to mimic innate responses to viral infection. Ingestion of OPCs resulted in enhanced 
innate antiviral responses in vivo, also increased expression of TNF $\alpha$ protein production.

Studies have shown an inverse relationship between the consumption of apples and the risk of several cancers. The peels of apple, which have been shown to possess exceptionally high concentrations of antioxidants, are often discarded. Our data demonstrated that APE, obtained from organic Gala apples, imparted significant reduction in the viability of a variety of cancer cell lines. Further, this data showed a significant decrease in growth and clonogenic survival of human prostate carcinoma and breast carcinoma. Furthermore, APE treatment resulted in a marked concentration-dependent decrease in the protein levels of proliferative cell nuclear antigen, a marker for proliferation. In addition, APE treatment resulted in a marked increase in maspin, a tumor suppressor protein that negatively regulates cell invasion, metastasis, and angiogenesis. Apple peels should not be discarded from the diet (Shaw et al., 2010).

Norren et al., (2003) recorded that a combination of flavonoids selected on basis of effective flavonoid xanthine oxidase inhibition and superoxide scavenging resulted in increased superoxide scavenging.

Huanga et al. (2009) Natural phenolic compounds play an important role in cancer prevention and treatment. Phenolic compounds from dietary plants such apple include phenolic acids, flavonoids, and others. Various bioactivities of phenolic compounds are responsible for their chemopreventive properties, e.g., antioxidant, anticarcinogenic, or antimutagenic and anti-inflammatory effects.

The effect of apple peel on serum IgG levels gave increase in animals fed on supplemented diets with apple peel for six weeks then put under stress . In animals after suppressed their immune system, serum IgG level was decreased in week 0 and 2. On the other hand, increases in IgG level were observed after 4 and 6 weeks when compared to negative control (ELSayed, 2007).

Boyer and Liu (2004) demonstrated that the rats fed on apple juice also had a decreased level of malondialdehyde (MDA), a marker of lipid peroxidation. Quercetin, a major flavonoid in apples, had no effect on lipid oxidation when ingested by rats, suggesting that quercetin alone is not responsible for the apple's ability to inhibit lipid oxidation (Breinholt et al., 2003). 
Other antioxidants and the interaction between the different apple antioxidants, including quercetin, may contribute to the antioxidant activity of apples, ingestion of high levels of a 1:1 mixture of apple juice and black currant juice increased the antioxidant status of the blood and decreased lipid oxidation (Young et al., 1999).

One possible implication is also that the low-vegetable diets, which contained $170 \mathrm{~g}$ vegetables/10 MJ, supplied enough dietary antioxidants and that the high-vegetable diets, which contained $810 \mathrm{~g}$ vegetables, berries, and apples/10 MJ, provided no additional protection against lipid peroxidation (Freese et al., 2002).

Aprikian et al., (2003) reported that Apples may have selective effects on abnormalities associated with the plurimetabolic syndrome. Therefore, the effects of $20 \%$ lyophilized apple supplementation on plasma and tissue lipids and on protection against susceptibility to oxidative stress and renal dysfunction were investigated in Zucker lean or obese rats. The heart concentration and urinary excretion of malondialdehyde were reduced by apple consumption in obese Zucker rats, suggesting better protection against peroxidation. Glucosuria and proteinuria in obese Zucker rats were also suppressed by the apple diet. despite their moderate fiber content, apples improve substantially the lipid status and peroxidative parameters in obese Zucker rats.

Diet supplement with (apple peel $75 \mathrm{~g} / \mathrm{Kg}$ diet + Honey $100 \mathrm{~g} / \mathrm{Kg}$ diet + Yogurt $150 \mathrm{~g} / \mathrm{Kg}$ diet) were evaluated for their effects on lipid peroxidation of spleen tissue. The values of MDA obtained for the group of animals are given in tested supplemented diet (suppressed their immune system before feeding) reduced the MDA when compared to positive control group. In the other experiment (suppressed their immune system after feeding) the tested diet reduced the MDA when compared to negative control group (EL-Sayed, 2007).

The selected flavonoid mixture significantly lowered intestinal oxidative stress indicated by malondialdehyde concentration when compared with sham-fasted animals. Furthermore, oxidative stress measured as this flavonoid mixture when compared with control significantly lowered plasma malondialdehyde concentration in fed rats (Norren, et al., 2003). 


\section{Conclusion:}

Results of the present study recommend that the important role to apple peel where hence they play a good role in raising the efficiency of the immune system and body protection against diseases. However, Millions of pounds of waste apple peels are generated in the production of applesauce and canned apples each year. We proposed that a valuable food ingredient could be made using the peels of these apples if they could be dried and ground to a powder without large losses of phytochemicals and use it as food additive to support and production functional food. The feeding before stress was the best. 


\section{References}

Aprikian, O., Busserolles, J., Manach, C., Mazur, A., Morand, Ch., Davicco,M. J., Besson, C., Rayssiguier, Y., Rémésy, Ch. and Demigné, Ch. (2003): Lyophilized Apple Counteracts the Development of Hypercholesterolemia, Oxidative Stress, and Renal Dysfunction in Obese Zucker Rats1. J. Nutr. 133:1860-1865.

Aprikian,O., Duclos,V., Guyott, S., Besson,C., Manach, C., Bernalier,A., Morand,Ch., Rémésy,Ch. and Demigne,Ch.(2003): Apple Pectin and a Polyphenol-rich apple concentrate are more Effective Together Than Separately on Cecal Fermentations and Plasma Lipids in Rats. J. Nutr. June 1,133: 1860-1865.

Barham, D. and Trinder, M. (1972): Quantitative enzymatic colorimetric determination of uric acid in serum, plasma or urine. Analyst. 97: 142.

Bazzano L. A; He, J.; Ogden L. G.; Loria C. M. and Whelton P. K. (2003): Dietary fiber intake and reduced risk of coronary heart disease in US men and women: the National Health and Nutrition Examination Survey I Epidemiologic Follow-up Study. Arch. Intern. Med. Sep. 8;163(16):1897-904.

Begona, R. L.; Leal, A.M.; Liza, M.; Lacort, M. and Degroot, H. (1994): Antioxidant effects of esteradiol and 2- hydroxy estradiol on ironinduced lipid peroxidation of rat liver microsomes. Steroids, 59:388-389.

Boyer, J. and Liu R. H. (2004): Apple phytochemicals and their health benefits. Nutr. J. 12, 3 (1) :5.

Breinholt, V., Nielson S., Knuthsen, P., Lauridsen, S., Daneshvar, B., Sorensen, A.(2003): Effects of commonly consumed fruit juices and carbohydrates on redox status and anticancer biomarkers in female rats. J. Nutr. Cancer. 45:46-52.

Chapman, D. G.; Castilla, R. and Campbell, J. A. (1959): Evaluation of protein in food. Method for the determination of protein efficiency ratio. Can .J. Biochem. Phsiol., 1: 679- 686.

Cho, E.; Seddon, J. M.; Rosner, B.; Willett, W. C. and Hankinson, S. E. (2004): Prospective study of intake of fruits, vegetables, vitamins, and carotenoids and risk of age-related maculopathy. Arch Ophthalmol. 122(6):883-92.

Daughenbaugh, K. F., Holderness, J., Graff, J. C., Hedges, J. F., Freedman, B., Graff, G.W. and Jutila, M. A. (2011): Contribution of transcript stability to a conserved procyanidininduced cytokine response in $\gamma \delta \mathrm{T}$ cells. Genes and Immunity, 10.1038 . 
Duncan, D. B.(1955): Multiple range and multiple F test. Biometrics 11: 1-42.

EL-Sayed, E.G. (2007): Effect of diets fortificated with some antioxidants and certain biological materials on the experimental rats immune system. Ph. D. Thesis, Fac., Specific Education. Ain Shams, University.

Fawcett, D.W. and Scott (1960): Bloom and Fawcetl textbook of histology $5^{\text {th }}$ Ed Saunders, USA.542-550.

Fernandez, M. L. (2001): Soluble fiber and nondigestible carbohydrate effects on plasma lipids and cardiovascular risk. Curr Opin Lipidol. 12(1):3540.

Fossati, P. (1980): Quantitative enzymatic colorimetric determination of uric acid in serum, plasma or urine. Clin. Chem., 26:227.

Freese, R., Alfthan, G., Jauhiainen, M., Basu, S., Erlund, I., Salminen, I., Aro, A. and Mutanen, M. (2002): High intakes of vegetables, berries, andapples combined with a high intake of linoleic or oleic acid only slightly affect markers of lipid peroxidation and lipoprotein metabolism in healthy. Am. J. of Clinical Nutr., (76), 5, 950-960.

Graig, A. (1998): Saunders manual of clinical Laboratory Science. Lehmann, 1st Ed. 833:958.

Hedges, J., Kimmel, E., Jerome, M., Holderness, J., Snyder, D., Kemoli,S. and Jutila1, M.(2011): Oligomeric procyanidins stimulate innate antiviral immunity, J. Immunol. (3): 186-187.

Hegested, D. M.; Mills, R. C.; Elvehijem, C. A. and Hart, F. B. (1941): Choline in the nutrition of check. J. Biol. Chem. 138:459.

Heinerman, J.(1995): Heinerman's New encyclopedia of Fruits and Vegetables. Prentice Hall.236-356.

Henry, R. J. (1964): Colormeteric method to determination serum total protein. Clin. Chem. 7: 181-245.

Holderness, J., Daughenbaugh, K., Kimmel, E., Freedman, B., Hedges, J., Jackiw, L. and Jutila, M.(2011): Select procyanidins prime the T cell by modulating transcriptome degradation. J. Immunology, 186, 154.9.

Huanga,Wu. Y., Caia, Y. Z. and Zhangb, Y. (2009): Natural Phenolic Compounds From Medicinal Herbs and Dietary Plants: Potential Use for Cancer Prevention. Nutrition and Cancer 62: 1, 1-20.

Huxley, R. R. and Neil, H. A. W. (2003): The relation between dietary flavonol intake and coronary heart disease mortality: a meta-analysis of prospective cohort studies. Eur. J. of Clin. Nutr. 57, 904-908.

Kern, M.; Tjaden, Z.; Ngiewih, Y.; Puppel, N.; Will, F.; Dietrich, H.; Pahlke, G. and Marko, D. (2005): Inhibitors of the epidermal growth 


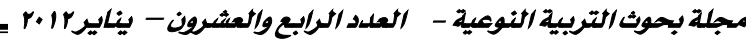

factor receptor in apple juice extract. Mol. Nutr. Food Res. 9;49(4):317-328.

Knekt, P.; Jarvinen, R.; Reunanen, A. and Maatela, J. (1996): Flavonoid intake and coronary mortality in Finland. a cohort study. BM.J. Feb. 24;312 (7029): 478-81.

Liu, R.H.; Liu, J. and Chen, B. (2005): Apples prevent mammary tumors in rats. J. Agric. Food Chem. 23;53(6):2341-3.

Nemi, C. J. (1986): Schalm's Veterrinary Hematology. Lea and Fiibiger. Philadelphia, Abstract.USA.

Norren, k.V., Danny, E. C., Robert, J., Petra, G., Zandrie, H.,Paul, A. M., (2003): Effects of Preoperative Flavonoid Supplementation on Different Organ Functions in Rats. J. Nutr. 133:1860-1865.

Puel, C.; Quintin, A.; Mathey, J.; Obled, C.; Davicco, M.J.; Lebecque, P.; Kati-Coulibaly, S.,; Horcajada, M. N. and Coxam, V. (2005): Prevention of bone loss by phloridzin, an apple polyphenol, in ovariectomized rats under inflammation conditions. Calcif Tissue Int. 2005 Nov;77(5):311-8. Epub Nov 16.

Reitman, S. and Frankel, S. (1957): Acalorimetric methods for the determination of serum glutamic-oxaloacetic and glutamic -pyrovate transaminase. Am. J. Clin. Path. pp 28-56.

Riley, M. J. (1981): Stress: Physical Symptoms; Causes of Stress. Eur. J. Immunol., 23:1552-1560.

Schalm, O. V. (1986): Veterinary Hematology. 4th ed., Lea \& Febiger, Philadelphia, PP.21-86.

Shaw, S. R., Eggert, D., Mukhtar, H. and Ahmad, N. (2010): Antiproliferative Effects of Apple Peel Extract Against Cancer Cells. J. Immunology. 62, 4:517-524.

Van Der Sluis, A. A.; Dekker, M. and Skrede, G. (2002): Activity and concentration of polyphenolic antioxidants in apple juice. 1. Effect of existing production methods. J. Agric. Food Chem. Dec. 4;50(25):7211-9.

Webster, D. (1974): Colorimetric method to determine serum albumin Clin. Chem. Acta, 53: 109-112.

Wiedermann, U.; Hanson, L. A. and Dehlgren, U.I. (1993): Impaired mucosal antibody response to cholera toxin in vitamin A-deficient rats immunized with oral choleral vaccine. (published erratum appears in Infect. Immuno.) 61: 3952-3957.

Wintrobe, M. M. (1967): The wintrobe Erythrocytic Indexes. Clinical hematology. $6^{\text {th }}$ ed. Lea \&Febigor, Phila-PP: 414-419. 
The protective and therapy effect of apple peel on the experimental rats

Wolfe, K. L. and Liu, R. H. (2003): Apple Peels as a Value-Added Food Ingredient. J. Agric. Food Chem., 51 (6), 1676-1683.

Wolfe, K., Wu, X. and Liu, R. H. (2003): Antioxidant Activity of Apple Peels. J. Agric. Food Chem., 51 (3), 609-614.

Young, D.S. (1975): Quantitative determination of alkaline phoshatase in serum. Clin. Chem., 21:15.

Young, J., Nielson, S., Haraldsdottir, J., Daneshvar, B., Lauridsen, S., Knuthsen, P., Crozier, A., Sandstrom, B., Dragsted, L.(1999): Effect of fruit juice intake on urinary quercetin excretion and biomarkers of antioxidative status. Am. J. Clin. Nutr. , 69:8794. 